\title{
Influencing Individual Perceptions of Deep Level Diversity in Virtual Learning Teams (VLT)
}

\author{
Jaime Newell \\ University of Arkansas \\ Department of Information Systems \\ Walton College of Business \\ Fayetteville, AR 72701 \\ JNewell@,walton.uark.edu \\ Cynthia Riemenschneider \\ Information Systems Department \\ Hankamer School of Business \\ One Bear Place \#98005 \\ Baylor University, Waco, TX 76798-8005 \\ cindy_riemenschneider@baylor.edu
}

\author{
Lionel Robert \\ University of Arkansas \\ Department of Information Systems \\ Walton College of Business \\ Fayetteville, AR 72701 \\ LRobert@,walton.uark.edu \\ Likoebe Maruping \\ University of Arkansas \\ Department of Information Systems \\ Walton College of Business \\ Fayetteville, AR 72701 \\ LMaruping@walton.uark.edu
}

\begin{abstract}
Two emerging trends are impacting both universities and corporate training programs: virtual learning and diversity. Virtual Learning Teams (VLT) learn by solving intellectual and cognitive tasks that require the sharing and utilization of information to achieve learning objectives. VLT members are separated by spatial distance and do not have the same opportunities to communicate as do traditional learning teams. Compounding the operational challenge of establishing and maintaining VLT member relationships is the fact that their members are often non-traditional students who tend to be diverse in terms of demographics, work experience, and beliefs compared to traditional teams. Naturally, this creates challenges in facilitating social integration. One way in which social integration may be enhanced is through leveraging the very communication technology that VLTs are reliant upon. Results of our study provide insight into how communication technology can support learning.
\end{abstract}

\section{Introduction}

Two emerging trends are impacting both universities and corporate training programs: virtual learning and diversity [1-5].Virtual Learning Teams (VLT) are training teams composed of members who are dispersed across spatial and temporal boundaries and who communicate primarily through information and communication technologies [6]. These training teams learn by solving intellectual and cognitive tasks that require the sharing and utilization of information to achieve learning objectives. VLTs encounter unique challenges that traditional teams do not face. VLT members are separated by spatial distance and do not have the same opportunities to communicate as do traditional learning teams. For example, while in traditional learning teams, members may chat face-to-face in the classroom or engage in informal exchange on campus, VLT members often do not have this opportunity. As a result, virtual teams, in general, tend to be more taskoriented [7] and are less likely to exchange informal personal information than traditional collocated teams [8, 9]. This represents a significant disadvantage for VLTs, as the relational aspect of team work is important to team learning [10-12] While the study of the impact of physical and temporal seperation is an important one, prior research has explored these effects by examining differences between collocated and virtual teams. Further exploration of these differences is beyond the scope of this study. For our purposes, all of the teams we study are virtual and their performance is necessarily impacted by their separation. Holding dispersion constant, we focus on the factors that separate low performing and high performing VLTs.

The operational challenge of establishing and maintaining VLT member relationships is 
compounded by the fact that their members are often non-traditional students who are likely to be more diverse in demographics, work experience, and beliefs, compared to collocated traditional teams [13]. This poses additional challenges to instructors of VLTs, because team diversity has been linked to decreases in member satisfaction, team cohesion, and sometimes performance [14-19]. Team diversity influences these team constructs through its impact on social integration and knowledge composition [17]. Although team diversity holds much promise,.it also poses several challenges. Diverse teams are often composed of members who differ in their perspectives, beliefs, and experiences-a factor which can be beneficial by contributing a variety of knowledge to the learning process. However, from a relational perspective, diversity can be problematic and lead to communication difficulty and conflicting

exchanges between members of the class and learning teams.

Thus, the primary research question is: How does the use of an e-identity profile influence individual perceptions of diversity in virtual learning teams? There is an abundance of research that focuses on surface-level diversity (age, gender and race) in traditional teams [20]. However, research has shown these variables often lose their influence over time and deep-level diversity (beliefs, attitudes, and knowledge) often have more enduring impacts [15]. As a result, in this study, we examine deep-level diversity. Additionally, there have been several calls in recent research $[17,21,22]$ for the examination of task type as a moderator of diversity's impact. These scholars have suggested that it may be an important influence on factors affecting performance. For example, tasks involving the resolution of a conflict

$\mathrm{H} 4$

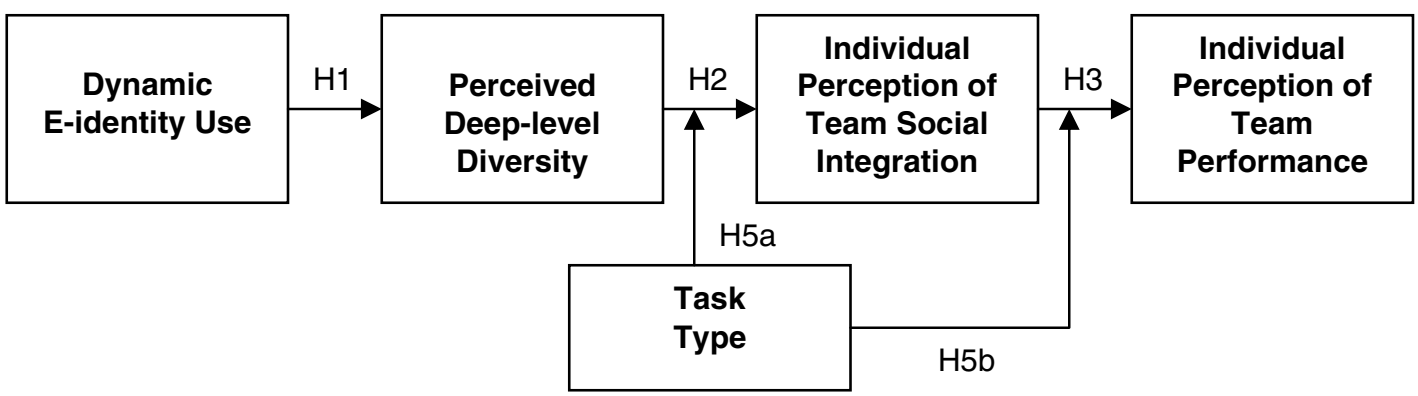

Figure 1. Research model

viewpoints which may inhibit social integration within the team [17].

One way in which social integration may be enhanced is through leveraging the very communication technology that teams are so reliant upon. In this study, we propose that by providing VLT members with information about team member characteristics (via identity profiles similar to those created for social networking websites such as myspace.com and facebook.com), they should have the opportunity to more readily exchange personal information. We refer to these profiles as e-identity profiles. They represent a collection of self-selected information about a team member's identity. This information might range from simple demographics, such as age, gender, and ethnicity, to more psychologically-based traits, such as personality, preferences, and interests. In terms of practical use, eidentities could be employed in a setting which involves completely virtual interaction - an online class or training program. It would also be practical to incorporate them as a part of a class which uses elearning software, such as Blackboard, to supplement of power, may impact team relationships differently than a task which involves the generation of ideas. The implication is that certain interventions aimed at impacting team processes (e.g. team member relationships) may be a wasted effort if, due to the nature of the task, performance is not reliant upon these processes. It addition to wasted resources, another implication is that interventions aimed at certain team attributes may be detrimental to performance. An intervention designed to heighten a team's sense of shared identity may hurt performance if a shared identity decreases team members' inclination to challenge their teammates on ideas which might lead to performance improvements. Thus, in this research, we also examine the moderating impact of task type. This paper is intended to contribute to our understanding of the role of information technology in support of learning in virtual environments.

\section{Theoretical background and hypotheses}


Figure 1 provides a summary of the research model.

\subsection{Diversity: Background and theory}

Researchers generally agree on two theoretical lenses that best explain how diversity functions in social settings. Social Identity Theory and Selfcategorization Theory are the most widely cited [17]. Social Identity Theory (SIT) explains how cognitive and motivational forces influence identification within and across groups. This theory predicts that members of a group will establish a group identity and show preference for members of their in-group, over out-group members. Identification with the ingroup becomes a behavioral motivator which pushes team members to conform to the collective norms, wishes, and values of the group but can also lead to negative opinions about out-group members [23, 24].

Self-categorization Theory (SCT) states that people tend to group themselves and others into social categories based on various attributes. This helps individuals organize information about other individuals into predefined categories [25]. Together, these two theories explain why individuals prefer to interact with others they perceive as similar, as opposed to dissimilar others. In summary, both SIT and SCT explain how perceptions of diversity impact social integration.

\subsection{Perceived diversity}

Individuals' perceptions of deep-level diversity can be influenced by exposing team members to information that emphasizes similarity among team members. Initial perceptions of diversity create a biased lens [26]. This lens alters how individual team members interpret team interactions [27]. As a result, during team discussions, members are likely to emphasize information that confirms their perceptions of team member similarity. This perception can hold up even when disconfirming information is exchanged during team discussions [28]. When team members perceive themselves to be part of an in-group (based on perceived deep-level similarities) they psychologically minimize the significance of differences that may emerge [28]. Thus, even in the face of subsequent disconfirming information, perceptions of low deep-level diversity are likely to persist.

As a result, regardless of the level of actual deeplevel diversity, when team members are initially lead to believe that they share the same deep-level characteristics as their team members they are likely to pay attention to information that confirms their initial perceptions. In summary, we expect that, with all other things being equal, virtual teams whose members are initially exposed to information emphasizing their similarities will have lower levels of perceived deep-level diversity than virtual teams with no initial information.

H1: Individuals in VLTs that use e-identities, with information emphasizing team member's similarity, will have lower levels of Perceived deep-level diversity (PDD).

Attitudinal and value similarity is associated with higher team cohesiveness [29], and satisfaction [30]. However, attitudinal and value diversity have been shown to be associated with decreased satisfaction, commitment [31] and conflict [32]. Studies of deeplevel diversity and attitudinal or value-similarity generally attribute these findings to psychological attraction. In general, individuals find it more pleasurable to interact with those who are similar to them [33]. These interactions, with similar others, reinforces and verifies one's beliefs, attitudes, and behaviors [34]. Similarity among team members is positively related to trust, cohesive and other social integration components [35].

The evaluation of relative similarity in deep-level attributes is based on perception, since deep-level attributes are unobservable. Research related to group identification supports this argument. Identification with a group is said to be a "perceptual cognitive construction that is not necessarily associated with any specific behaviors or affective states" [36]. To identify with a group, an individual need only feel that their interests, values, and behaviors are similar to those of the group. If one feels that the group is not relatively homogeneous, it would follow that they would not feel a sense of identification and integration with the group. Based on these findings and arguments, we hypothesize:

H2: Perceived Deep-level Diversity (PDD) will negatively influence a VLT member's perception of team social integration.

\subsection{Team social integration}

Social integration is a positively associated with group processes [10, 31, 37]. O'Reilly and his colleagues [31] found that groups with low social integration had higher turnover rates than groups with high social integration. A primary dimension of social integration, cohesiveness, is consistently found to positively impact team performance $[14,15,38$, 39]. Researchers theorize that "teams with a higher level of social integration are more willing to subjugate individual interests for team goals that 
should direct member resources toward higher team task performance" [15]. In this same vein, others have found that team members' perception of having a common group identity reduced the amount of group conflict [40].

Extant research shows that diversity does not directly impact team performance, but rather, functions through a mediating process. Social integration is the most commonly studied process, as it reflects a number of related concepts (cohesiveness, satisfaction with the group, and willingness to work with the group in the future) which predict performance [37]. A number of studies show that diversity affects team outcomes through social integration, or some subset of it $[14,15,17,31$, 37]. Thus, consistent with prior research, we hypothesize:

H3: VLT member's perception of social integration will positively influence their perception of team performance.

H4: The impact of perceived deep-level diversity on $V L T$ member's perception of team performance will be mediated by their perception of team social integration.

\subsection{Task type}

Depending upon the extent of interdependence required by a task, the effect of diversity on social integration and performance may be different. For example, a task which requires the generation of ideas [creativity task] requires that team members rely primarily on their individual skills and knowledge to fulfill the task requirements. Assigning this type of task to a team may result in more ideas, but a creativity task can reasonably be accomplished by an individual, thus it has a lower level of interdependence. A cognitive-conflict task, on the other hand, ultimately requires consensus and cannot be executed by an individual. Team members are required to communicate and defend their position, while at the same time, responding to others' positions. Thus, this task requires more interdependence.

Based upon the level of task interdependence, we argue that the impact of perceived deep-level diversity on social integration will be moderated by task type because certain tasks require more interdependent interaction. If a team is able to work relatively independently on-for example, a creativity task - they might be more likely to develop a higher level of social integration than they would with a negotiation task. This is because team members are less reliant upon one another to complete a creativity task. Their perceived differences would not impact their extent of social integration as much because their perceived differences are not as much of an impediment to the completion of the task. Thus, we hypothesize:

H5a: Task Type will moderate the impact of Perceived Deep-level Diversity on VLT member's perceptions of team social integration, such that when a task requires a low level of interdependence [creativity task], the effect will be weaker than it is for a task which requires a higher degree of interdependence [cognitive-conflict task].

Not only does the level of task interdependence impact the relationship between perceived diversity and social integration, we also believe it will impact the relationship between social integration and team performance. As mentioned, different tasks require varying levels of interdependence. Social integration is more beneficial when a task requires a high degree of interdependence, such as with a consensus task, because social integration results in normative pressure to conform and cooperate for the sake of maintaining the group identity, according to Social Identity Theory [23, 24]. On the other hand, a task that requires idea generation is more reliant upon the cognitive or creative abilities of the individual, than it is on the cooperation of the team. In short, task type determines the need for a certain level of cooperation or interdependence, which in turn, is impacted by the degree of social integration. If a task does not require much cooperation, social integration may not significantly and positively impact performance. In fact, one might argue that it may be detrimental to performance because the normative pressure accompanying social integration may serve to discourage "outside-the-box thinking". In an ideageneration task, it is possible that this would have a negative effect on performance. Thus:

H5b: Task Type will moderate the impact of VLT member's perceptions of team social integration on their perception of team performance, such that when a task requires a low level of interdependence [creativity task], the effect will be weaker than it is for a task which requires a higher degree of interdependence [cognitive-conflict task].

\section{Research methodology}

To test these hypotheses, we used a 2 X 3 factorial design, crossing two task types (creative/cognitive-conflict) with three levels of diversity (high/low/control). Seventy-seven students 
from a medium-sized, southern university participated in the experiment. $67 \%$ were male, $33 \%$ were female, and the average age was 22 years old. The participant pool was $87 \%$ White, $5 \%$ Asian/Pacific Islander/Indian, and 5\% Black/Non T Hispanic, and 3\% Native American/Alaskan Native/Hawaiian Native.

\subsection{Procedure}

Upon arrival to the study setting, each participant was assigned to an enclosed workstation and asked to draw a random user id. The user ids were designed to protect anonymity, be free of information related to gender, race, or personal preferences, and to assign participants to a particular group and condition. Group size ranged from 3 to 5 individuals. Participants were then asked to $\log$ in and complete a computer-based profile (e-identity profile) containing a variety of questions related to demographics, values/attitudes/beliefs, personality/ cognition, knowledge/skills/abilities, and personal interests/preferences. After submitting their profile, participants were instructed to review their team members' profiles. When an individual accessed a team member's profile, they were shown a dynamically-generated page which displayed the profile in a manner congruent with the condition to which the group was assigned. Groups were assigned to one of three conditions: low diversity, high diversity, or the control condition. Teams in the low diversity condition saw only the information in their team members' profiles which matched the information in their own profile, while teams in the high diversity condition saw information which did not match. For the control condition, there was no manipulation of the information. These teams saw all information contained in team members' profiles.
Once the profiles had been generated and reviewed by all team members, participants logged in to a computer-based chat application (using their anonymous id) which allowed them to collaborate on the completion of two tasks. After each task, participants were instructed to fill out a survey measuring their perception of team diversity, social integration, and performance. The order of the tasks was randomized in order to reduce the possibility of order effects. Our analysis shows that there was no significant difference in the results based upon the order the tasks were performed. After completing the two tasks and surveys, participants were debriefed and dismissed.

\subsection{Task type description}

In order to operationalize task interdependence, we selected task types from McGrath's Group Task Circumplex [41], which offers a framework for categorizing task types in a mutually exclusive, yet comprehensive manner. Since creativity and generation tasks lie on the opposite ends of the vertical cooperation-conflict axis, they are best suited to examination of how task type moderates the relationship between perceived diversity and social integration, as well as, social integration and performance. At the one end is the creativity task which requires the least amount of interdependence among group members, while the cognitive-conflict task requires the most.

For the creativity task, participants were asked to work as a team to generate solutions to the University's parking problem. This task was selected because the lack of parking on campus is a problem that is highly relevant to student subjects, draws upon their personal experience, and has been widely used by previous researchers [42-44]. Participants were

Table 1a: Descriptive Statistics and Intercorrelations for Creativity Task

\begin{tabular}{lcccccc}
\hline \multicolumn{1}{c}{ Variable } & M & SD & 1 & 2 & 3 & 4 \\
\hline 1. PDD-General & 2.3 & 0.8 & -- & & & \\
2. PDD-Relevant & 2.1 & 0.7 & $.647(* * *)$ & -- & & \\
3. Social Integration & 2.2 & 0.9 & $-.606(* * *)$ & $-.652(* * *)$ & -- & \\
4. Team Performance & 2.6 & 1.0 & $-.569(* * *)$ & $-.538(* * *)$ & $.556(* * *)$ & -- \\
\hline$* \mathrm{p}<.10^{* *} \mathrm{p}<.05 * * * \mathrm{p}<.01$ & & & & & &
\end{tabular}

Table 1b: Descriptive Statistics and Intercorrelations for Cognitive-conflict Task

\begin{tabular}{lcccccc}
\hline \multicolumn{1}{c}{ Variable } & M & SD & 1 & 2 & 3 & 4 \\
\hline 1. PDD-General & 2.3 & 0.8 & -- & & & \\
2. PDD-Relevant & 2.1 & 0.7 & $.567(* * *)$ & -- & & \\
3. Social Integration & 2.2 & 0.9 & $-.466(* * *)$ & $-.759(* * *)$ & -- & \\
4. Team Performance & 2.6 & 1.0 & $-.286(* * *)$ & $-.652(* * *)$ & $.614(* * *)$ & -- \\
\hline
\end{tabular}

$* \mathrm{p}<.10 * * \mathrm{p}<.05 * * * \mathrm{p}<.01$ 
given 25 minutes to work together to generate and develop as many potential solutions as possible, and 5 minutes to record them. The cognitive-conflict task was the Legislative Dilemma [41]. This task has been widely used as a negotiation and conflict task [4547]. Participants were given 15 minutes to read the instructions and record their individual preferences, followed by 30 minutes for discussion and recording of their group's decision.

\subsection{Measures}

All measures were adapted from previously validated scales. Perceived deep-level diversity was assessed with 13 items taken from Harrison et al [15]. These items reflected perceptions of diversity in values, attitudes, interests, personalities, priorities, conflict and communication styles, skills, and experience, among others. These were measured on a $7 \mathrm{pt}$ Likert-type scale ranging from "not at all" to "to a great extent". Following Harrison et al's [15] lead on measuring social integration, we combined measures of cohesiveness, the co-worker scale of the Job Descriptive Index, and individuals' willingness to work with their teammates in the future. We standardized and averaged these ratings to obtain an overall measure of social integration. Finally, team performance was assessed via self-report from a fouritem measure $(\alpha=.88)$ [48].

\subsection{Instrument validation}

For the data set associated with the creativity task, alpha coefficients of .90 and .88 , respectively. For the data set associated with the cognitive-conflict task, the Cronbach's alpha coefficients for social integration and team performance are .93 and .89, respectively. The diversity construct, however, did not behave as expected. The items for perceived deep-level diversity load on two separate factors for each data set. This subsequent analysis suggests two dimensions of perceived deep-level diversity. Based upon the nature of the items, we have chosen to term these two constructs Perceived Deep-level Diversity: General (PDD-General), and Perceived Deep-level Diversity: Task Relevant (PDD-Relevant). The former refers to the perception of diversity as it relates to general deep-level characteristics, such as general values, attitudes, interests, etc. The latter refers to the perception of diversity as it relates to a particular task, such as commitment to working hard on the task and relevant experience for a task. For the creativity task, the Cronbach's alpha coefficients for PDD-General and PDD-Relevant are .88 and .90, respectively. For the cognitive-conflict task, they are .88 and .85 , respectively. Descriptive statistics for study variables are shown in Table $1 \mathrm{a}$ and $1 \mathrm{~b}$.

\subsection{Manipulation check}

As a manipulation check, we examined the data to see whether perceptions of deep-level diversity were being influenced by actual deep-level diversity [15]. Measures of actual deep-level diversity were collected from the profiles that participants completed. The results show that actual deep-level

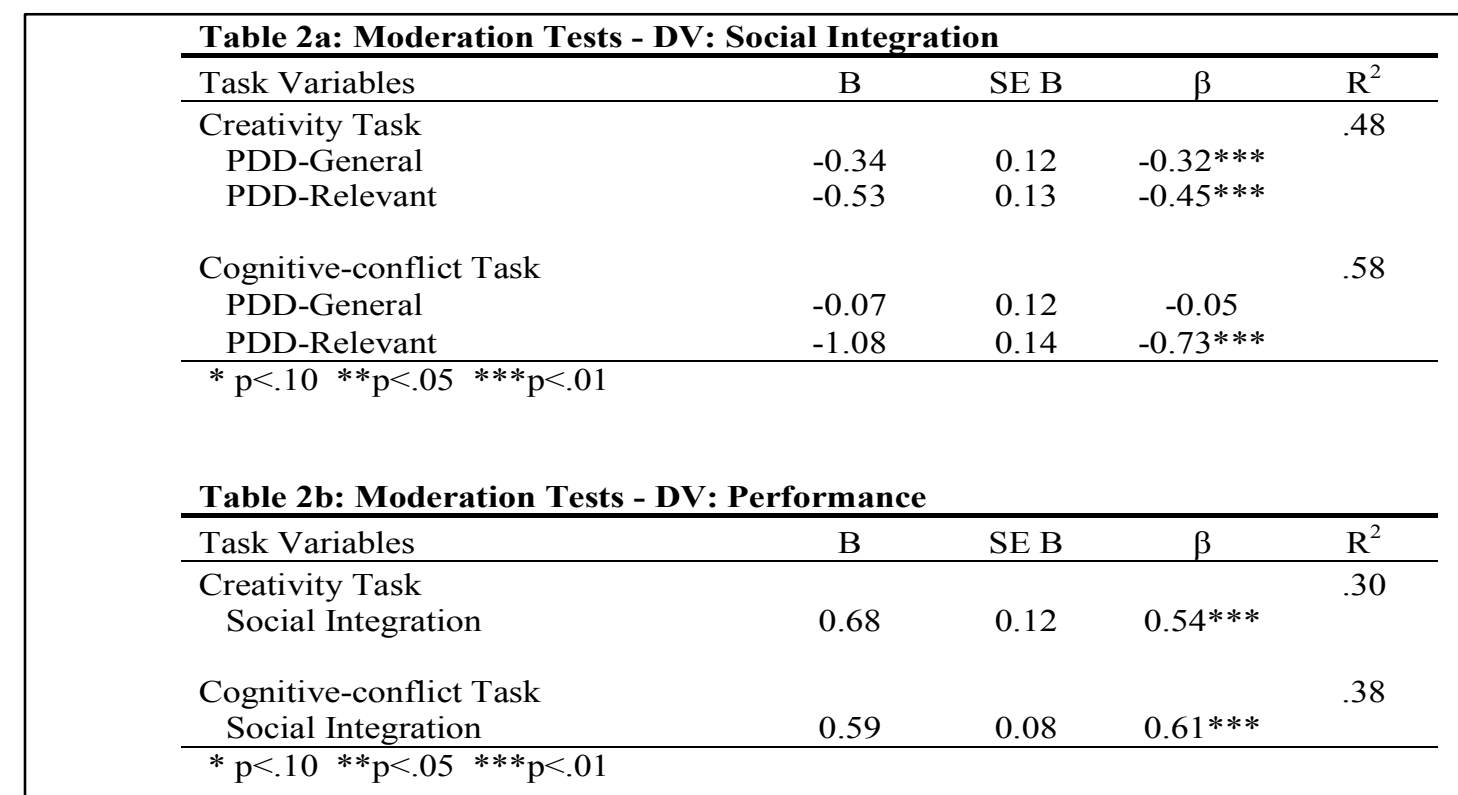

social integration and team performance have an acceptable degree of reliability, with Cronbach's diversity in general and task-relevant attributes does not significantly predict PDD-General (creativity 
task: $\beta=.04, p>.10$, cognitive-conflict task: $\beta=.09$, $\mathrm{p}>.10$ ) or PDD-Relevant (creativity task: $\beta=.09, \mathrm{p}$ $>.10$, cognitive-conflict task: $\beta=.14, \mathrm{p}>.10)$. We concluded that the manipulation was successful.

\section{Analysis and Results}

\subsection{E-identity profiles: Impact on perceived diversity}

Hypotheses 1 predicted that, the use of similar or dissimilar E-identity profiles will influence the coefficient for the high diversity group was significant and positive $(B=.53, p<.001)$, while the low diversity group was also significant, but negative $(\mathrm{B}=-.39, \mathrm{p}<.01)$. The overall variance explained by the treatment groups on PDD-General was $24 \%$. For PDD-Relevant, the model is not significant $(\mathrm{p}>.10)$.

In terms of the cognitive-conflict task, the results are similar. The overall model with PDD-General as the dependent variable is significant $(p<.005)$. The unstandardized coefficient for the high diversity variable was significant and positive $(B=.46, p<$ $.01)$, while the low diversity variable was also

\begin{tabular}{|c|c|c|c|}
\hline \multicolumn{2}{|c|}{ Hypothesis } & \multirow{2}{*}{$\begin{array}{c}\text { Support? } \\
\text { Partial }\end{array}$} & Observed Outcome \\
\hline H1 & $\begin{array}{l}\text { Individuals in VLT who use e-identities, } \\
\text { with information emphasizing team } \\
\text { member's similarity, will have lower of } \\
\text { Perceived deep-level diversity (PDD). }\end{array}$ & & $\begin{array}{l}\text { For both task types, PDD-General is influenced by } \\
\text { E-id profile, but not PDD-Relevant }\end{array}$ \\
\hline $\mathrm{H} 2$ & 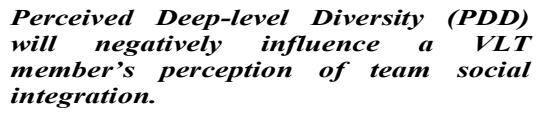 & Partial & $\begin{array}{l}\text { Both types of PDD negatively impact social } \\
\text { integration for creativity task, for cog-conflict task, } \\
\text { only PDD-Relevant negatively influences social } \\
\text { integration }\end{array}$ \\
\hline H3 & $\begin{array}{l}\text { VLT member's perception of social } \\
\text { integration will positively influence their } \\
\text { perception of team performance. }\end{array}$ & Confirmed & $\begin{array}{l}\text { Social integration positively influences } \\
\text { performance for both task types }\end{array}$ \\
\hline $\mathrm{H} 4$ & $\begin{array}{l}\text { The impact of perceived deep-level } \\
\text { diversity on VLT member's perception of } \\
\text { team performance will be mediated by } \\
\text { their perception of team social } \\
\text { integration. }\end{array}$ & Partial & $\begin{array}{l}\text { For creativity task, social integration partially } \\
\text { mediates effect of both PDD variables on } \\
\text { performance, For cog-conflict task, social } \\
\text { integration only mediates effect of PDD-Relevant } \\
\text { on performance }\end{array}$ \\
\hline H5a & $\begin{array}{l}\text { Task Type will moderate the impact of } \\
\text { Perceived Deep-level Diversity on a VLT } \\
\text { members perceptions of team social } \\
\text { integration, such that when a task } \\
\text { requires a low level of interdependence } \\
\text { Icreativity task], the effect will be weaker } \\
\text { than it is for a task which requires a } \\
\text { higher degree of interdependence } \\
\text { lcognitive-conflict task]. }\end{array}$ & Partial & $\begin{array}{l}\text { Effect of PDD-Relevant on Social integration is } \\
\text { weaker for creativity task, PDD-General does not } \\
\text { affect social integration for cog-conflict task }\end{array}$ \\
\hline $\mathrm{H} 5 \mathrm{~b}$ & $\begin{array}{l}\text { Task Type will moderate the impact of } \\
\text { VLT member's perceptions of team } \\
\text { social integration on their perception of } \\
\text { team performance, such that when a } \\
\text { task requires a low level of } \\
\text { interdependence Icreativity task], the } \\
\text { effect will be weaker than it is for a task } \\
\text { which requires a higher degree of } \\
\text { interdependence Icognitive-conflict } \\
\text { task]. }\end{array}$ & Confirmed & $\begin{array}{l}\text { Effect of social integration on performance is } \\
\text { weaker for creativity task than it is for the cog- } \\
\text { conflict task. }\end{array}$ \\
\hline
\end{tabular}

perception of deep-level diversity in a VLT. Since our instrument analysis suggested the presence of two deep-level diversity constructs, we examined the data in order to observe an impact of the manipulation on both General and Relevant PDD. There were 27 participants (9 groups) in the high diversity condition, 27 participants (8 groups) in the low diversity condition, and 23 participants ( 7 groups) in the control condition. We regressed each diversity construct on these two unweighted effects variables for each data set. For the creativity task, the overall model with PDD-General as the dependent variable, is highly significant $(\mathrm{p}<.001)$. The unstandardized significant, but negative $(\mathrm{B}=-.31, \mathrm{p}<.05)$. The overall variance explained by the treatment groups on PDD-General was $16 \%$. For PDD-Relevant, the model is not significant $(\mathrm{p}>.10)$. For both the creativity and cognitive-conflict tasks, we were not able to influence perceptions of deep-level diversity for those attributes which are more task-relevant. H1 is partially supported.

\subsection{Effect of perceived deep-level diversity on social integration}


To test H2, which hypothesized that PDD will negatively influence social integration, we regressed social integration on the two types of PDD. For the creativity task, the overall model is significant $(\mathrm{p}<$ .001 ) and explains $48 \%$ of the variance in social integration. PDD-General is significant and negative $(\beta=-.32, p<.001)$, while PDD-Relevant is also significant and negative $(\beta=-.45, p<.001)$. The cognitive-conflict task shows slightly different results. The overall model is significant $(p<.001)$, but PDD-General is non-significant in predicting social integration $(\beta=-.05, p>.10)$. PDD-Relevant is significant $(\beta=-.73, p<.001)$. This model explains $58 \%$ of the variance in social integration. $\mathrm{H} 2$ is partially confirmed and we thus conclude that the two types of diversity do negatively influence social integration for the creativity task, but not for the cognitive-conflict task. For the cognitive-conflict task, only PDD-Relevant influences social integration.

\subsection{Effect of team social integration on team performance}

H3 predicts that social integration will have a positive influence on performance. To test this hypothesis, we regressed team performance on social integration. The results show a positive, significant relationship $(\beta=.26, p<.05)$ between the two variables for the creativity task. Social integration explains $29 \%$ of the variance in team performance, after controlling for PDD-General and PDD-Specific $\left(\Delta \mathrm{R}^{2}=.10\right)$. For the cognitive-conflict task, the results are similar. The effect of social integration on performance is positive and significant $(\beta=.29, \mathrm{p}<$ $.05)$. The model explains $37 \%$ of the variance in performance, after controlling for the effects of PDDGeneral and PDD-Specific $\left(\Delta \mathrm{R}^{2}=.10\right)$. H3 is confirmed and we conclude that social integration does positively influence team performance for both task types.

\subsection{Mediating effect of social integration}

We hypothesized that the impact of perceived deep-level diversity on team performance would be mediated by social integration. To test this hypothesis, we followed Baron and Kenny's [49] steps for mediation analysis. Results indicate that this variable partially mediates the impact of the two diversity constructs on team performance [49].

With regards to the mediation analysis for the cognitive-conflict task, the data do not support our hypothesis of mediation. This analysis fails at the first step, as both independent variables are not significantly related to performance. However, for the cognitive-conflict task, social integration did mediate the effect of PDD-Relevant on performance, but not PDD-General. H4 is partially supported.

\subsection{Moderating effects of task type}

H5a predicts that task type will moderate the impact of perceived deep-level diversity on social integration. Because we have separate data sets, it was not possible create a dummy variable for task type. Thus, it was impossible to create interaction terms with the task type variable. Table 2 a shows the main effects of the relationship between PDD and social integration for both the creativity and cognitive-conflict task. For PDD-General, the beta coefficient is larger for the creativity task, but it is non-significant for the cognitive-conflict task. Since PDD-General does not significantly affect social integration for the cognitive-conflict task, we cannot compare these two coefficients. In the case of PDDRelevant, beta coefficients for both tasks are significant. In comparing the standardized beta coefficients of the two task types, the effect of PDDrelevant on social integration is weaker for the creativity task. H5a, which predicted that the effect of PDD on social integration will be weaker for the creativity task, is partially confirmed. Table $2 \mathrm{~b}$ shows the main effects of the relationship between social integration and performance for both the creativity and cognitive-conflict task. Table 3 shows a summary of the hypotheses and outcomes of our analysis.

\section{Discussion}

The purpose of this research was to expand our understanding of diversity and task type. Specifically, we explored the possibility of influencing perceptions of deep-level diversity through the use of e-identity profiles and examined the moderating impact of task type. We found that it was possible to influence perceptions of diversity in general deep-level attributes, but not those deep-level attributes that are more relevant to the task. Given that neither actual diversity, nor the manipulation, appears to influence perceptions of task-relevant PDD, it may be these perceptions are formed as a result of direct experience working with team members. Though the identity profile contained questions related to task type experience and relevant skills, individuals' experience working with their team members potentially overshadowed the effect of the e-identity profile. Another possibility is that there were not enough task-specific characteristics contained in the 
profiles to allow individuals to form these perceptions. To further explore these possibilities, future plans for this line of research will involve a qualitative analysis of the content of team chat sessions, in an attempt to identify whether teams were exchanging information which might have run counter to the intended manipulation (perceptions of high/low/no diversity).

\subsection{Theoretical contributions/implications}

The current study makes several theoretical contributions that must be examined in light of the limitations of the study. First, our sample of participants was not highly diverse, with regards to surface-level attributes (ie. $67 \%$ male, $86 \%$ white). Future research should examine these findings with a sample which is more reflective of the population of students and business professionals to which we generalize. Second, there are any number of unmeasured actual diversity variables which may affect performance. The focus of our study is on perceived deep-level diversity and thus we did not analyze the impact of actual deep-level diversity, or surface-level diversity. There is clearly a need to study these additional dimensions of diversity, but given the complexity of the current study, we reserve these directions for future research.

Given the above limitations, we do feel that this study makes several important theoretical contributions. First, we provide insight into the relationship between diversity and individuals within virtual teams. A second contribution to the literature is the step made towards resolving some of the contradictory findings in diversity research. By showing that task type has an influence on the relationship between diversity and social integration, we add empirical evidence to the theory that diversity is less beneficial when task requirements for interdependent interaction are low. Lastly, our study contributes to the literature of teaching and learning by examining the role of IT in support of learning.

\subsection{Conclusion}

Diversity and virtual learning are two emerging trends that impact both universities and corporate training programs. Both diversity and virtual learning has advantages and disadvantages. This study provides insight into how communication technology can be leveraged to reduce the disadvantages.

\section{References}


Analysis and Implications," Journal of Management, vol. 29, no. 6, pp. 801, 2003.

[18]K. A. Jehn, G. B. Northcraft, and M. A. Neale, "Why Differences Make a Difference: A Field Study of Diversity, Conflict, and Performance in Workgroups," Administrative Science Quarterly, vol. 44, no. 4, pp. 741-763, 1999.

[19]L. H. Pelled, K. M. Eisenhardt, and K. R. Xin, "Exploring the Black Box: An Analysis of Work Group Diversity, Conflict, and Performance," Administrative Science Quarterly, vol. 44, no. 1, pp. 1-28, 1999.

[20]L. L. Martins, L. Gilson, L., and M. T. Maynard, "Virtual teams: What do we know and where do we go from here?," Journal of Management, vol. 30, no. 6, pp. 805-835, 2004.

[21]J. B. Shaw, and E. Barrett-Power, "The effects of diversity on small work group processes and performance," Human Relations, vol. 51, no. 10, pp. 1307-1325, 1998.

[22]L. H. Pelled, "Demographic diversity, conflict, and work group outcomes: An intervening process theory," Organization Science, vol. 7, no. 6, pp. 615-631, 1996.

[23]H. Tajfel, Differentiation Between Social Groups: Studies in the Social Psychology of Intergroup Relations: Published in cooperation with European Association of Experimental Social Psychology by Academic Press, 1978.

[24]H. Tajfel, and J. C. Turner, "An integrative theory of intergroup conflict," The social psychology of intergroup relations, pp. 33-47, 1979.

[25]J. C. Turner, "Social categorization and the self-concept: A social cognitive theory of group behavior," Advances in group processes: Theory and research, vol. 2, pp. 77-121, 1985.

[26]W. B. Swann Jr, J. T. Polzer, D. C. Seyle et al., "Finding value in diversity: Verification of personal and social selfviews in diverse groups," Academy of Management Review, vol. 29, no. 1, pp. 9-27, 2004.

[27]K. G. Shaver, An introduction to attribution processes: Cambridge, Mass.: Winthrop Publishers, 1975.

[28]M. B. Brewer, J. M. Manzi, and J. S. Shaw, "In-group Identification as a Function of Depersonalization, Distinctiveness, and Status," Psychological Science, vol. 4, no. 2, pp. 88-92, 1993.

[29]J. R. Terborg, C. Castore, and J. A. DeNinno, "A longitudinal field investigation of the impact of group composition on group performance and cohesion," Journal of Personality and Social Psychology, vol. 34, no. 5, pp. 782-790, 1976.

[30]D. B. Turban, and A. P. Jones, "Supervisor-subordinate similarity: types, effects, and mechanisms," J Appl Psychol, vol. 73, no. 2, pp. 228-34, 1988.

[31]C. A. O'Reilly, D. F. Caldwell, and W. P. Barnett, "Work group demography, social integration, and turnover," Administrative Science Quarterly, vol. 34, no. 1, pp. 21-37, 1989.

[32]S. G. Barsade, A. J. Ward, J. D. F. Turner et al., “To Your Heart's Content: A Model of Affective Diversity in Top Management Teams," Administrative Science Quarterly, vol. 45, no. 4, pp. 802-836, 2000.

[33]M. McPherson, L. Smith-Lovin, and J. M. Cook, "Birds of a Feather: Homophily in Social Networks," Annual Review of Sociology, vol. 27, no. 1, pp. 415-444, 2001.
[34]W. B. Swann, A. Stein-Seroussi, and B. R. Giesler, "Why people self-verify," Journal of Personality and Social Psychology, vol. 62, no. 3, pp. 392-401, 1992.

[35]C. Julian, C. Mueller, R. M. Wachter et al., "Top management teams of international join ventures in Thailand: the effects of heterogeneity on group processes and goal attainment," Journal for International Business and Entrepreneurship Development, vol. 2, no. 1, pp. 1-12, 2004.

[36]B. E. Ashforth, and F. Mael, "Social identity and the organization," Academy of Management Review, vol. 14, no. 1, pp. 20-39, 1989.

[37]E. Mannix, and M. A. Neale, "What Differences Make a Difference?," Psychological Science in the Public Interest, vol. 6, no. 2, pp. 31-55, 2005.

[38]L. Chidambaram, "Relational Development in ComputerSupported Groups," MIS Quarterly, vol. 20, no. 2, pp. 143$165,1996$.

[39]M. G. Gonzalez, M. J. Burke, A. M. Santuzzi et al., "The impact of group process variables on the effectiveness of distance collaboration groups," Computers in Human Behavior, vol. 19, no. 5, pp. 629-648, 2003.

[40]M. Mortensen, and P. J. Hinds, "Conflict and shared identity in geographically distributed teams," International Journal of Conflict Management, vol. 12, no. 3, pp. 212-238, 2001.

[41]J. McGrath, E. , Groups: Interaction and Performance, Englewood Cliffs, New Jersey: Prentice-Hall, Inc. , 1984.

[42]T. Connolly, L. M. Jessup, and J. S. Valacich, "Effects of Anonymity and Evaluative Tone on Idea Generation in Computer-Mediated Groups," Management Science, vol. 36, no. 6, pp. 689-703, 1990.

[43]C. F. Gettys, and S. D. Fisher, "Hypothesis plausibility and hypothesis generation," Organizational Behavior and Human Performance, vol. 24, no. 1, pp. 93-110, 1979.

[44]L. M. Jessup, T. Connolly, and J. Galegher, "The Effects of Anonymity on GDSS Group Process with an IdeaGenerating Task," MIS Quarterly, vol. 14, no. 3, pp. 313-321, 1990.

[45]B. E. Mennecke, J. S. Valacich, and B. C. Wheeler, "The Effects of Media and Task on User Performance: A Test of the Task-Media Fit Hypothesis," Group Decision and Negotiation, vol. 9, no. 6, pp. 507-529, 2000.

[46]H. Topi, J. S. Valacich, and M. T. Rao, "The Effects of Personality and Media Differences on the Performance of Dyads Addressing a Cognitive Conflict Task," Small Group Research, vol. 33, no. 6, pp. 667, 2002.

[47]J. S. Valacich, B. E. Mennecke, R. M. Wachter et al., "Extension to Media Richness Theory: A Test of the TaskMedia Fit Hypothesis." pp. 11-19.

[48]D. G. Ancona, and D. F. Caldwell, "Demography and design: Predictors of new product team performance," Organization Science, vol. 3, no. 3, pp. 321-341, 1992.

[49]R. M. Baron, and D. A. Kenny, "The moderator-mediator variable distinction in social psychological research: Conceptual, strategic, and statistical considerations," Journal of Personality and Social Psychology, vol. 51, no. 6, pp. 11731182, 1986. 